\title{
DDT stalemate stymies malaria control initiative
}

$\mathrm{L}$

ucky Mirembe recalls that it was getting dark as the cluster of men arrived at her home. They made her wait outside as a man - wearing thick, black rubber gloves up to his elbows and a blue helmet with a face screen - meticulously began to spray the inside walls of her mud hut.

At first, Mirembe was confused. She didn't know what the spray was. "They said it would help with the malaria," she says quietly as she sits on a banana leaf mat, her 9-year-old son Charles nestled beside her. "It made my eyes hurt. It smelled bad."

The bad smell was DDT (dichlorodiphenyl-trichlorethane), a synthetic pesticide with a sordid past and now, a controversial present, in the small East African country of Uganda, which is proposing its use to combat rising malaria rates.

It's a disease that Mirembe knows first-hand. She's suffered 2 miscarriages because of it. Her daughter died of the disease 2 years ago, while her son, Charles, is brain-damaged after a bout of cerebral malaria.

"I thought the disease came from eating too many mangoes," she says, describing her vain attempts to stop her children from eating the succulent fruit. "Why do we suffer? Why must we keep dying?"

According to the Ministry of Health in Uganda, 320 people die every day of malaria, and those are only the reported cases. Malaria is the biggest killer of children under 5 , the number one reason for visits to clinics and hospitals and the number one reason for miscarriages.

It is also a plague of the poor.

"It is probably the biggest reason that people stay in a cycle of poverty and can't get out from that," says Dr. Jessie Stone, a physician from New York City and the director of Soft Power Health, an organization aimed at educating people about malaria.

Last April, after almost 4 years of contentious debate among government, exporters, politicians and environmentalists, the Ministry of Health began spraying DDT in Oyam and Apac, 2 districts in Northern Uganda, estimat-

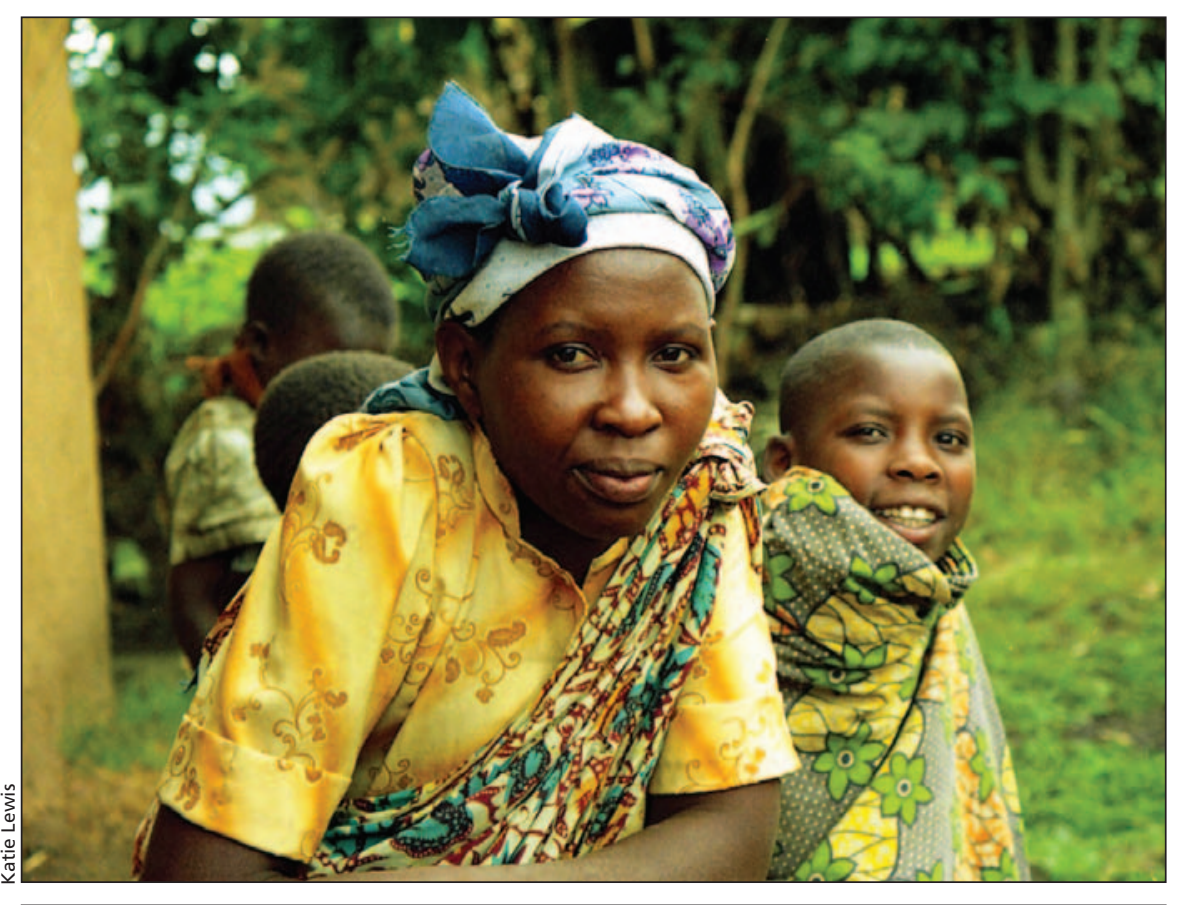

Lucky Mirembe and her son, Charles. Charles is brain damaged due to cerebral malaria. Three years ago Mirembe's daughter, Betty, aged 4, died of the disease.

ing that it would cost at least US\$8 million to spray the 15 areas of the country that are hardest hit by malaria. In aid of that goal, the United States Agency for International Development, under the umbrella of the US\$1.2 billion President's Malaria Initiative, allocated the required monies.

The scientific evidence suggested the spraying program would have a positive effect. DDT kills the mosquitoes when they enter the home and creates a sort of protection bubble causing the mosquitoes to go elsewhere to find their next blood meal. Several other countries, including South Africa and Mozambique, had modest DDT spraying programs within their borders and soon discovered that malaria rates dropped.

The Ugandan government also viewed it as an integral part of its antimalaria strategy. "It must be a multipronged approach," says Dr. Myers Lugemwa of the Ministry of Health's Malaria Control Programme. "I'm not saying DDT is a magic bullet. It cannot work alone, even when you spray, you have to treat the people because they already have the parasites in them."
But DDT comes with a nasty reputation, which opponents were quick to seize upon as they sought to discontinue the spraying program in Uganda.

Recognized as 1 of 12 toxic, persistent chemicals by the Stockholm Convention on Persistent Organic Pollutants, DDT was banned in North America during the 1970s and fell out of favour around the world. But in 2006, the World Health Organization approved its use for health-related reasons, particularly indoor residual spraying of walls.

A scant 6 weeks after the government began spraying DDT, a group of traders, exporters and environmentalists filed a petition in Kampala's High Court accusing the Ugandan government of not following spraying guidelines, whether those of the WHO or those of Uganda's National Environment Management Authority.

Spraying was halted immediately.

Yet, for people like Mirembe, DDT had provided a measure of hope. "Maybe it will help my family," she says, pensively watching her largely uncommunicative son chase chickens around the yard. "We have suffered too much." 
That is indeed true of Apac, which has the dubious honor of having the highest recorded malaria rate in the world. "The rates are staggering," says Stone. "People living in the area are bitten by malaria-infected mosquitoes about 1500 times a year."

That means every single day, each person in the district is bitten by at least 4 mosquitoes carrying the parasite that causes malaria.

Mirembe's hopes, though, are slowly dissipating as the impasse continues.

Although the Ugandan government believes nothing but DDT will suffice in trying to control the mosquitoes that transmit malaria, opponents continue to protest its use.

Back in the bustling capital of Kampala, more than 200 worried and angry people have gathered at an anti-malaria protest organized by Ken Lukyamuzi, the leader of the opposition party.

Two smartly dressed businesswomen in their mid-30s hold up a sign on which the words "DDT kills" are scrawled.

"Down with DDT," reads another sign.

Lukyamuzi is far from moderate he accuses the Ugandan government of poisoning its own people. But he maintains his concern is for people's health and the environment — and not just about politics.

"It is clear that DDT is dangerous to man," he says in Luganda, the local language, gesturing to the crowd. "You can protect yourself. ... Get your saw, your machete, your axe! Greet the spraymen at your house."

While few others would counsel such violence, scientists say the envi- ronmental concerns of opponents like Lukyamuzi are valid.

"It's important to remember that DDT is persistent organic pollutant, which means that the substance stays in the environment for a very long time. And a lot of our exports to Europe, North America might suffer as a result of having DDT," says Steven Nyanzi, head of the the chemistry department at Makerere University. "All of a sudden we just want to use DDT."

Will such environmental concerns trump the health benefits? For now, no DDT is being sprayed in Uganda but the government's intent is to resume spraying when it can. The question now is: how long will each side hold out? Katie Lewis, Apac, Uganda

DOI:10.1503/cmaj.081585

\section{DISPATCH FROM THE MEDICAL FRONT}

\section{Hard work, harder numbers}

$\mathrm{B}$ irth is hard work, no matter what part of the planet you call home.

But I learnt that women giving birth in rural South Africa suffer more than others because of one simple fact: numbers $(\operatorname{read} \$)$.

That's right: debt.

The maternity ward at the Church of Scotland Hospital in Tugela Ferry, where I recently worked, was 30 million rand (\$5 million) overbudget in 2007.

That is hard to believe given that we regularly ran out of linens, hand soap, sterile gloves, paper towels, fetal heart monitor ink, paper and belts, chlorihexidine, gauze, amnihooks, KY jelly and proper-sized suture material.

There were definitely no women demanding their epidurals at this hospital (and no midwives pushing them).

You were lucky if you had a cotton sheet to lie on. And I never heard one complaint about the 32 degree Celsius heat in the labour ward (there were no fans or air conditioning).

Certainly the Health Department of Kwa-Zulu Natal has a lot on its plate: take for instance, the province's fight

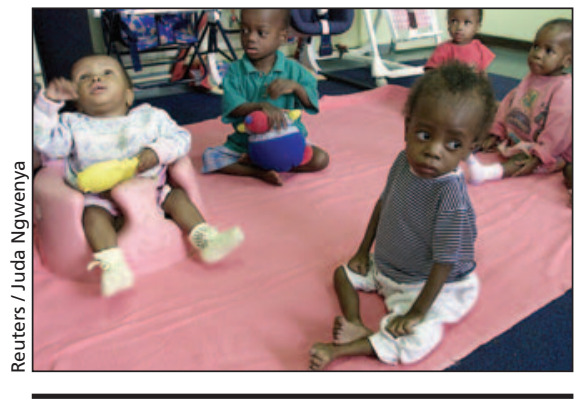

Two-year-old Sifiso is one of the 200 babies who are born HIV-positive every day in South Africa.

against multi- and extreme-drugresistant tuberculosis that goes hand in hand with the province's HIV epidemic. In 2004, $40.7 \%$ of antenatal clinic attendees in the province of Kwa-Zulu Natal were HIV positive the highest rate in all of South Africa.

Happily, thanks to the Prevention of Mother to Child Transmission Program, close to $100 \%$ of the women who delivered at the Church of Scotland Hospital knew their status, and almost all of those who were positive had selfadministered nevirapine at the onset of labour, and their babies were given a dose within the first 72 hours of life.

Still, major challenges continue to plague the South African Prevention of Mother to Child Transmission Program. For example, although aiming to provide a 6-month supply of formula to HIVpositive mothers, district hospitals are often out of stock, leading to mixed feeding.

Lack of follow-up of mothers and their HIV-exposed infants results in some babies not receiving nevirapine after birth, and women not receiving the antiretroviral treatment they so desperately need.

Certainly for a woman like Zanele, an HIV-positive 30-year-old mother of 3 , who has a young family to raise, a properly funded program would go a long way to ensuring that her children have a mother and an HIV-free childhood. — Lindsay Tabah, Hamilton, Ont.

\section{DOI:10.1503/cmaj.081414}

CMAJ invites contributions to "Dispatches from the medical front," in which physicians and other health care providers offer eyewitness glimpses of medical frontiers, whether defined by location or intervention. Submissions, which must run a maximum 400 words, should be forwarded to: wayne.kondro@cma.ca 